\title{
Harry Potter e o Sujeito da Pós-Modernidade
}

Harry potter and the citizen of the after modernity

Harry potter y el sujeto de la pos-modernidad

Daniela Botti da Rosa

Universidade Federal de Alagoas

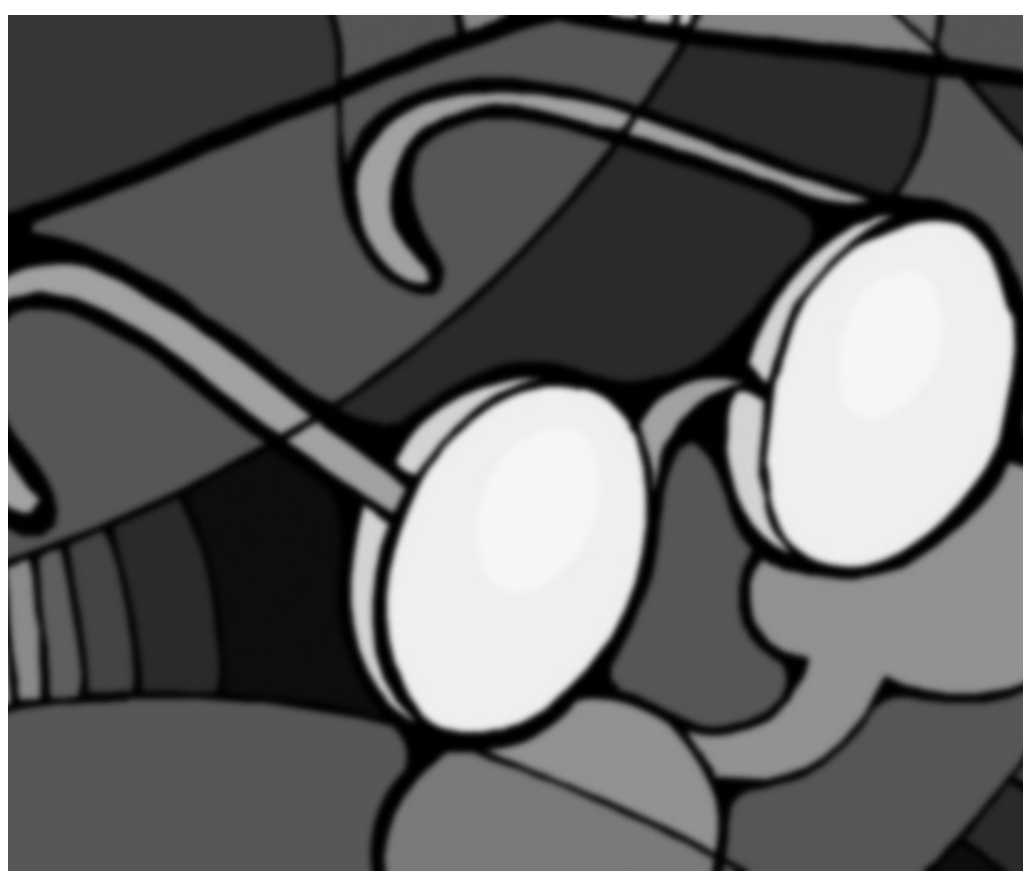


Resumo: O presente artigo, uma reflexão crítica sobre o sujeito da contemporaneidade a partir de um de seus produtos - a literatura, especificamente a saga de Harry Potter - parte de quatro premissas básicas ligadas à teoria psicanalítica. As duas primeiras ligam-se aos estudos de Bruno Bettelheim acerca dos contos de fadas, e mostram as possibilidades de identificação do sujeito com as histórias infantis bem como a necessidade e pertinência do acesso à fantasia no mundo anímico da criança. A terceira toma de empréstimo a uma analista junguiana - Marie Louise von Franz - a noção de que as histórias podem funcionar como compensação de algo que está faltando aos sujeitos ou a uma época. A quarta premissa traz a marca da releitura freudiana feita por Jacques Lacan acerca da carência paterna no mundo contemporâneo, que se manifesta - entre outras possibilidades - na dissolução de traços nítidos de demarcação entre gerações e no afrouxamento do ato educativo. Procuramos questionar, neste artigo, partindo desses pressupostos, como a saga de Harry Potter pode sustentar novos traços identitários a partir de novas condições de subjetivação.

Palavras-chave: Harry Potter. Contemporaneidade. Herói. Identificação.

Abstract: The present article, a critical reflection of the citizen of the after modernity, from one of its products - literature, specifically the histories of Harry Potter - part of four on basic premises the psychoanalysis. The two first ones league the studies to it of Bruno Bettelheim concerning fairy-tales, showing the possibilities of identification of the citizen with infantile histories, as well as the necessity and relevancy of the access to the fancy in the children's psychic world. Third it takes by loan to one analyst - Marie Louise von Franz - the notion of that histories can have the function as compensation of that it is lacking to the citizens or to a time. The fourth premise brings the mark of the Freud's reading made by Jacques Lacan, concerning the paternal lack in the world contemporary, who if manifest - among others possibilities - in the dissolution of clear traces of landmark between generations and in the dilution of the educative act. We look for to question, in this article, leaving of these estimated, as the histories of Harry Potter can support new identification traces from new conditions of construction of the citizen.

Keywords: Harry Potter. After-modernity. Hero. Identification.

Resumen: El presente artículo, una ponderación crítica sobre el sujeto de la contemporaneidad desde uno de sus productos - la literatura, específicamente la saga de Harry Potter - parte de cuatro premisas básicas ligadas a la teoría psicoanalítica. Las dos primeras se ligan a los estudios de Bruno Bettelheim acerca de los cuentos de hadas, y muestran las posibilidades de identificación del sujeto con las historias infantiles así como la necesidad y pertinencia del acceso a la fantasía en el mundo anímico del niño. La tercera toma prestada una analista junguiana - Marie Louise von Franz - la noción de que las historias pueden funcionar como compensación de algo que está faltando a los sujetos o a una época. La cuarta premisa trae la marca de la relectura freudiana hecha por Jacques Lacan acerca de la carencia paterna en el mundo contemporáneo, que se manifiesta - entre otras posibilidades - en la disolución de trazos claros de demarcación entre generaciones y en el aflojamiento del acto educativo. Buscamos cuestionar, en este artículo, partiendo de esos presupuestos, como la saga de Harry Potter puede sostener nuevos trazos de identidad desde nuevas condiciones de subjetivación.

Palabras-clave: Harry Potter. Contemporaneidad. Héroe. Identificación.

\section{Harry Potter e o Sujeito da Pós-Modernidade}

Inúmeras são as maneiras encontradas, através do imaginário na cultura, para a elaboração das questões existenciais. Lembremos que sujeito e cultura estão atrelados: tanto o sujeito fala através da cultura como vice-versa. São muitas as formas, as possibilidades de o sujeito se haver com o seu desamparo, bem como com o seu desejo, mediante as identificações. Porém, com as possibilidades identificatórias tradicionais esmaecidas, nos nossos dias, ele vai em busca de novos recursos identitários. (Lemos, 2005, p. 17)

Certo dia, em um reino não tão distante, percebeu-se que, dentro de cada pessoa, existia uma, ou várias histórias, e que as pessoas, por sua vez, podiam se reconhecer 
Segundo Corso e Corso (2006), o que impele a nova geração a preferir 0 vídeo-game, o computador e a televisão, em oposição aos livros, é a falta de uma literatura de qualidade. nas histórias que Ihes eram contadas. Era uma vez... em um tempo caótico, confuso, em uma sociedade em que a violência se tornava cada vez mais banal e corriqueira, em que os homens se destruíam uns aos outros sem motivos, ou mesmo pela falta de motivos. Era uma vez uma realidade dura, espinhenta, carente de mitos, em que o vazio moral e a falta de referências sociais faziam as pessoas idealizarem a vida em termos do que podiam ter, e não do que poderiam ser. Pois é nesse improvável cenário que surgiu, na literatura e, logo depois, no cinema, um bruxinho magricela, de cabelos despenteados, órfão de pai e mãe, que encantou crianças e adultos e trouxe um pouco de magia para a ordem do dia.

A infância e a juventude da pós-modernidade se exercem, com poucas exceções, em frente à televisão e ao computador. O mundo parece estar carente de histórias, e Harry Potter vem para nos contar algumas. Mas, o que faz da saga de Harry Potter algo singular que atrai os jovens de volta para os livros? Mais que isso, que encanto provoca uma corrida alucinada atrás dos livros e filmes após cada lançamento e a formação de grupos de fãs fanáticos, de modo semelhante ao que ocorreu algumas décadas atrás nos lançamentos de discos dos Beatles? Segundo Corso e Corso (2006), o que impele a nova geração a preferir o vídeo-game, o computador e a televisão, em oposição aos livros, é a falta de uma literatura de qualidade. Completaríamos dizendo que não apenas a qualidade da escrita e da história faz a diferença, mas também a necessidade de novos mitos e de histórias que façam com que as crianças e jovens, mesmo sem saber, se sintam compreendidos e identificados com as personagens, histórias que falem de nós, da nossa época e de nossas questões, histórias que, utilizando uma idéia de Freyre (2001), não apenas façam dormir as crianças, mas que também possam acordar os homens.

A interconexão entre psicanálise e literatura já nos foi indicada por Freud, quando este utiliza peças dramáticas como Édipo-Rei, de Sófocles, ou Hamlet, de Shakespeare, para articular questões pertinentes ao sujeito e à cultura. Partindo do modelo de interlocução freudiano, não buscamos, enquanto objetivo, analisar uma história, uma personagem ou ainda seu autor, mas interrogar uma trama. Podemos falar da relação entre as histórias infantis e a psicanálise a partir dos estudos de Bettelheim (1980) sobre os contos de fadas, nos quais nos é contado, através da interpretação de vários contos, que as crianças se identificam com as personagens, pois estas expressam ou personificam aspectos de seus dramas internos. Segundo esse autor, as histórias de fadas falam por metáforas, ou seja, expõem os dramas e conflitos da criança de forma simbólica, contexto em que ela pode se projetar, se identificar e se reconhecer apenas na medida das suas possibilidades. Os contos se tornam uma potencialidade não ameaçadora para a criança resolver ou buscar soluções para seus dilemas, por permitir que ela tenha certo controle sobre seus dramas internos através das histórias. Hoje em dia, muitos pais receiam as histórias fantasiosas por pensarem que elas não apresentam quadros verdadeiros da vida, quando, na verdade, eles tratam diretamente da realidade interior da criança; também têm medo que seus filhos mergulhem no mundo da fantasia e se afastem da realidade. Mas toda criança vive o mundo de forma fantástica, aproximandose da realidade adulta na medida em que se desenvolve. O mundo anímico da criança, como nos fala Bettelheim, é diferente do 
"Há um tempo certo para determinadas experiências de crescimento, e a infância é o período de aprender a construir pontes sobre a imensa lacuna entre a experiência interna e o mundo real"

(Bettelheim, 1980, p. 83). mundo dos adultos, e essa diferença precisa ser respeitada. Uma criança educada apenas com histórias realistas poderá ver suas fantasias como inadequadas e fechar-se em uma infância vazia, que, mais tarde, na adolescência ou na idade adulta, pode exigir sua compensação, levando às distorções fantasísticas da realidade. "Há um tempo certo para determinadas experiências de crescimento, e a infância é o período de aprender a construir pontes sobre a imensa lacuna entre a experiência interna e o mundo real" (Bettelheim, 1980, p. 83).

Foi a partir dessas premissas que nos pusemos a pensar na atratividade que tem Harry Potter para as crianças e os jovens dessa nossa caótica era pós-moderna. Iniciemos, então, com a estrutura dessa narrativa: o mundo de Harry Potter é dividido em duas comunidades, os bruxos e os trouxas, sendo esses últimos os que não trazem a magia no sangue. Quando trata da comunidade trouxa, a história nos mostra a nossa realidade cotidiana. Como exemplo, em vários momentos, na história, quando ocorre algum evento que reúne grande número de bruxos, para que estes não sejam descobertos pelos trouxas, são lançados feitiços que fazem com que estes, ao se aproximarem dos lugares mágicos, se lembrem de compromissos urgentes e se afastem correndo. Segundo Smadja (2004), o mundo dos trouxas é desencantado, enquanto, no dos bruxos, reina o mistério. Enfim, trouxas seriam aqueles que não percebem a importância da magia na vida das crianças e, porque não dizer, de jovens e adultos. Os não bruxos são apresentados como pessoas que não enxergam um palmo à frente do nariz, que estão preocupados demais com questões sem importância e que vêem o mundo de forma distorcida. Já a comunidade bruxa nos mostra os valores de que estamos carentes, de modo a equilibrar, através da literatura, algumas de nossas necessidades internas mais secretas. Tomamos aqui de empréstimo uma noção de Marie Louise von Franz, analista junguiana, que propôs, em seus estudos, que as histórias poderiam ter a função de compensar algo que está faltando na vida de um indivíduo, ou mesmo na vida de uma sociedade (Franz, 1990).

Dentre a imensa gama de necessidades humanas, seguindo uma linha de releitura freudiana realizada por Jacques Lacan, está a necessidade de uma metaforização da instância paterna. Para que um sujeito se constitua, sem ser através da psicose ou da perversão, é necessário que haja um corte, uma barreira, realizada via sujeitos e/ou instituições. Sobre a neurose contemporânea, já podemos ler em Lacan (2002):

Nossa experiência nos leva a designar sua
determinação principal na personalidade
do pai, sempre carente de alguma forma,
ausente, humilhada, dividida ou postiça.
É essa carência que, de acordo com nossa
concepção do Édipo, vem não só exaurir o
impulso instintivo como também prejudicar
a dialética das sublimaçóes. (p. 61)

No mundo pós-moderno, os sujeitos e entidades que estariam em condições de exercer essa função se tornaram marcados pelo não-fazer, pela omissão ou pela injustiça. No momento em que vemos políticos, policiais e chefes de Igrejas envolvidos em escândalos os mais variados, vemos também tomarem força os líderes de ficção. Na história, ocorrem alguns deslizes dentro do Ministério da Magia - geralmente cometidos por pessoas que estão sob efeito de feitiços - mas a grande figura de liderança, o diretor Alvo Dumbledore, marca seu lugar e sua postura por uma ética bem construída, 
híbrida de tradicionalismo e humanismo. Ainda os fios de fantasia tecidos em Harry Potter nos levam a um mundo onde a correção do caráter e o respeito ao outro são as características essenciais do herói. Ainda que tenha dúvidas constantes sobre si mesmo e suas ações, Harry segue uma ética deixada (quase) em abandono nos dias atuais. Além disso, contrapõe-se a muitas facetas da maldade, personificadas na personagem Voldemort, que nos remetem à violência e aos traços da crueldade contemporânea. Sobre isso nos fala Stahlschmidt (2006):

\begin{abstract}
Através da utilização de um cenário construído sobre os alicerces da magia, a autora traz, para o universo infantil, evocações a diferentes formas como observa o mal na contemporaneidade, atribuindo ao vilão da narrativa e seus seguidores atitudes como racismo, preconceito e intolerância, contra os quais lutam Harry e seus amigos. (p. 44)
\end{abstract}

Em Harry Potter e a Pedra Filosofal (Rowling, 2000b), o herói é apresentado como um bruxinho que cresceu sem saber de sua condição especial. Seus pais foram vítimas de um poderoso bruxo das trevas, Lord Voldemort, que não conseguiu matar Harry, ainda bebê, deixando-Ihe apenas uma cicatriz na testa. Nessa tentativa, o bruxo perdeu seus poderes e desapareceu, fazendo do menino sobrevivente um prodígio, um salvador do mundo dos bruxos, que estavam aterrorizados sob esse poder maligno. $\mathrm{Na}$ África e Ásia, segundo Ford (1999), a maioria dos contos tem início com o nascimento do herói de uma forma prodigiosa, que já nasce falando, andando e realizando proezas. Também é comum que os relatos da vida dos "salvadores" ou "iluminados" tenham início com um nascimento milagroso, como Buda, que nasceu andando, e Jesus Cristo, que nasceu de uma virgem fecundada pelo Espírito Santo. Talvez isso venha nos mostrar a necessidade interna que temos de um novo "salvador", pois acreditamos que, na configuração que o mundo tomou, não há mais saída, a não ser a milagrosa. Nessa primeira aventura, a chegada de uma carta explicando a Harry que ele é um bruxo famoso e que os pais deram a vida em sua defesa, convidando-o a freqüentar Hogwarts, a escola de magia, vem em hora crucial, quando ele está triste e desamparado, na véspera de seu $11^{\circ}$ aniversário, pois sabe que não vai ganhar carinho ou presentes. Que criança desamparada já não criou um dia a fantasia de que alguém chegaria e a tiraria do mundo de miséria - financeira ou emocional - em que vive? Talvez seja mais comum do que imaginamos o fato de crianças inventarem contos de fadas para fugir da sua realidade de exclusão e falta de afeto, criando um mundo em que é importante, mais que isso, em que são "salvadores". A nova realidade de Harry Potter parece-Ihe um sonho, ou melhor, realiza seus sonhos mais secretos. Muitas crianças têm, em determinado momento, a fantasia de não serem filhos dos seus pais, de pertencerem a uma outra família, mais nobre, como Harry Potter. Os tios, que o criaram, figuram aqui nesse sentido como os pais reais, altamente decepcionantes, e os pais que morreram ficam inatingíveis, idealizados. É o que Freud (1909/1976) chama de "Romances Familiares", nos quais "...a imaginação da criança entrega-se à tarefa de libertar-se dos pais que desceram em sua estima e de substituí-los por outros, em geral de uma posição social mais elevada" (p. 220). Há, portanto, uma fase em que a criança precisa se decepcionar com os pais, percebendo que eles não são tão onipotentes nem tão perfeitos como elas pensavam antes. E eis que surgem atualmente tramas ficcionais que preenchem essa necessidade, fazendo 
com que as crianças e adolescentes muitas vezes vivam mais intensamente nesses mundos alternativos, unindo-se em grupos de admiradores de uma determinada porção de fantasia (filmes, livros, jogos, etc.).

Segundo Viorst (2005), essa decepção é sentida como a perda dos heróis da infância, uma perda necessária para que a criança encontre novas pessoas para amar e imitar, e mesmo novas formas de amor. É necessário deixar morrer esses pais perfeitos para poder aceitar a imperfeição do mundo. Esse pode ser um dos componentes, associado a uma personalidade patológica, que leva filhos adolescentes a matarem, de fato, os pais, fato que vem acontecendo com maior frequência ultimamente. Talvez não estejamos aceitando passar para nossos filhos a nossa imperfeição, talvez os pais não consigam aceitar que os filhos se decepcionem com eles ou que tenham os sentimentos ambivalentes de amor e ódio. Sobre isso, era comum que os contos de fadas tivessem início com a substituição de um dos pais, em geral a mãe, por uma madrasta, o que tornava mais fácil para a criança projetar nessa figura má seu ódio e seus desejos inconscientes de destruição e preservar a boa mãe real de seus ataques sádicos. É um tema da vida inconsciente da criança desejar a morte dos pais, e também desejar ser amado tão profundamente, tão exclusivamente, pela mãe, a ponto de ela ser capaz de sacrificar a própria vida, como acontece com Harry.

"Perder" os pais (da imagem infantil) é necessário também para que a criança se volte para outros interesses, como o grupo de amigos, o aprendizado e a escola. É justamente nesse momento, para Harry, que aparece a Escola de Magia e Bruxaria de Hogwarts bem como os novos amigos
Rony e Hermione. Nesse momento, também, começam as aventuras iniciáticas do nosso pequeno herói, em que ele luta com monstros e desvenda mistérios. A simbologia da iniciação está presente nas histórias em que o herói precisa passar por provas para atingir algum objetivo. Isso lembra os tempos primitivos, quando essas provas realmente ocorriam para que o indivíduo mostrasse o merecimento de passar para uma nova fase da vida. Em todos os livros da série, Potter se vê às voltas com provas desse tipo, em especial em Harry Potter e o Cálice de Fogo (Rowling, 2001). Sabemos, com Campbell (1990), que os ritos de passagem serviam para que o corpo e a mente infantil fossem abandonados definitivamente, renascendo a antiga criança em um novo status, o de homens ou mulheres adultos e produtivos, com uma nova função social. $\mathrm{Na}$ possível ausência ou diluição de tais ritos na sociedade contemporânea, pergunta-se o que faz com que um indivíduo saiba que já é adulto? Isso se reflete em uma fase da vida em que não sabemos se somos crianças ou não, e ora exigem um comportamento infantil, ora exigem responsabilidade e controle de impulsos, como se esperaria de um adulto. A cada década, o tempo destinado à adolescência vai aumentando, adiando a vida adulta, e vão sendo criadas subfases, como a pré-adolescência. Além disso, a juventude é hoje, segundo Calligaris (2000), um ideal social, o que faz com que as pessoas se recusem cada vez mais a deixar a adolescência, mesmo com emprego e família, e isso gera, entre outras coisas, a atual prática de os pais tentarem ser "amigos" dos filhos.

Os pais, atualmente, se inibem em direcionar a vida dos filhos, proporcionando-lhes, por um prisma, liberdade, e, por outro, falta de investimento enquanto ato educativo, ou 
função educativa. É o que Corso (1993) chama de parentalidade envergonhada:

Temos então que a função não foi inibida, ela está na verdade sintomatizada, há sim um discurso que prega a não influência na subjetividade da criança surgindo sob a forma dos votos de que "seja feliz", de que "escolha seu próprio caminho", que "aprenda conforme o seu desejo", etc. Essa elevação do tão alardeado desejo da criança às alturas celestiais só corresponde à omissão, no mesmo discurso, do desejo parental. (p. 175)

Essa questão acerca da falta de transmissão entre as gerações, da inibição dos pais e das instituições em repassarem seus valores em nome da liberdade de formação do sujeito une vários aspectos de que tratamos neste artigo, como a decepção salutar dos filhos em relação aos pais - quando não se aceita mais o conflito entre gerações - bem como a questão da ausência de rituais de passagem e da valorização social da adolescência.

Atualmente, no nosso mundo trouxa, para além da fantasia, ou ainda com diferentes registros de fantasia, a função social de pertença que era dada pelos rituais pode ser transmitida às gangues, aos grupos racistas ou fundamentalistas. No passado, um menino de uma tribo hipotética só poderia fazer parte da caçada e ser considerado homem depois que tivesse matado o primeiro búfalo. Hoje os jovens costumam ouvir: "Você só pode andar com a gente se experimentar isso!", ou seja, a fantasia ligada a esses ritos e mitos se desloca. Draco é uma personagem que coloca, no início do primeiro livro, essa questão para Harry, mostrando-lhe que ele é o líder de um grupo, e que Harry poderia pertencer a esse grupo desde que pensasse e se comportasse como ele. Como Harry não aceita a proposta, torna-se seu inimigo. A aceitação ou não aceitação das regras de um grupo, de uma "tribo", determina a posição que o sujeito irá ocupar em relação a esse grupo. A escolha de Harry, na qual novamente encontramos valores de que a contemporaneidade carece, o coloca em oposição a um grupo influente e poderoso, na defesa de seu novo amigo Rony e daquilo que ele acredita estar correto. Na diluição da transmissão e transposição de valores entre pais e filhos, são os grupos identitários que tendem a dar esse contorno do que pertence ao semelhante e do que pertence ao diferente. Acerca do que falamos, conclui Calligaris (1993):

Se vocês esquecem, recalcam suas heranças,
suas origens familiares, históricas, etc., para
poderem ser indivíduos e eu fizer a mesma
coisa, seremos indivíduos iguais, definidos
apenas por nossa individualidade. Isso
garantiria um mundo de iguais. ...Só que
essas diferenças que cada um recalca vão
voltar de uma maneira particular. Não vão
voltar como lembranças de nosso passado.
Vão voltar nos levando a nos constituirmos
em grupos nos quais vamos sustentar uma
identidade imaginária - uma espécie de
caricatura de nossas referências culturais.
(p. 190)

No ápice dessa primeira história, Harry e os amigos salvam a pedra filosofal das mãos de Voldemort. Essa pedra era o ideal dos alquimistas da Idade Média, pois teria o poder de transformar qualquer metal em ouro e produzir o elixir da imortalidade, sendo este último um dos maiores desejos de Voldemort. Essa imagem pode simbolizar, na nossa sociedade, a tentativa eterna de vencer a morte, o tempo, já que, no espaço de uma vida, não conseguimos nos sentir plenos, já que o sentimento de vazio tem se tornado cada vez mais um companheiro humano, e busca-se a eternidade como forma de compensar essa falta, como se, tendo mais tempo, algum dia pudéssemos superar 
esse sentimento. Também essa questão estaria presente nos rituais de passagem e iniciação. Para passar a uma nova fase da vida, é preciso aceitar a morte de uma forma antiga, despir um invólucro simbólico, e vestir outro. A pedra filosofal é destruída no fim da história, fazendo-nos pensar que faz parte do processo de amadurecimento, tanto do indivíduo como da sociedade, o reconhecimento e a aceitação da nossa mortalidade, conforme Dumbledore, o diretor, explica a Harry:

\begin{abstract}
Afinal, para a mente bem estruturada, a morte é apenas a grande aventura seguinte. Você sabe, a Pedra não foi uma coisa tão boa assim. Todo o dinheiro e a vida que a pessoa podia querer! As duas coisas que a maioria dos seres humanos escolheriam em primeiro lugar. O problema é que os humanos têm o condão de escolher exatamente as coisas que são piores para eles. (Rowling, 2000b, p. 253)
\end{abstract}

Já no início do segundo livro, Harry Potter e a Câmara Secreta (Rowling, 2000a), o nosso herói está de volta à casa dos tios para passar as férias, novamente infeliz e maltratado. É nesse momento que a magia ressurge em sua vida para salvá-lo da decepcionante realidade, e então uma nova aventura começa. Dessa vez, ele e seus amigos precisam descobrir quem abriu uma câmara secreta no castelo e libertou um monstro existente dentro dela, que vem atacando e paralisando os alunos. Naturalmente, é Harry quem luta contra o monstro e o derrota. Nas mais variadas histórias, desde os contos de fadas, mitos, peças dramáticas e histórias modernas, o herói típico é aquela figura simbólica que faz o que precisa ser feito, pois sabe que esse é o seu destino. Ainda que não lhe agrade, muitas vezes, o rumo que toma, não há outra saída para ele se não tomá-lo.
Quem lê a saga de Harry Potter ou assiste aos filmes, sabe, desde o princípio, que terá de haver um conflito final entre o menino e Voldemort, um conflito do qual muitas vezes Harry gostaria de ser dispensado, tamanha a responsabilidade, mas ele sabe que não é possível. É a trajetória do herói, ele não vacila. O que coloca Harry sutilmente à distância do herói clássico - um herói pósmoderno? - é o fato de continuamente se questionar sobre suas ações e sobre seus sentimentos.

Já dizia Lacan (1997) sobre heróis típicos das tragédias de Sófocles: "Como eu lhes dizia outro dia, não há sombra de uma peripécia. Tudo está dado de saída, e as curvas não têm mais nada a fazer senão esmagarem-se umas sobre as outras" (p. 329). É assim para João e Maria, que não podem fazer outra coisa a não ser enfrentar a bruxa, ou Branca de Neve, que aceita os presentes da madrasta disfarçada, três vezes seguidas, não por falta de inteligência, mas por saber que esse era o seu destino, e que precisava passar pelo sono mortal para ressurgir madura e pronta para ser amada. Na seqüência da famosa história de Édipo, Antígona (Sófocles, 1997), filha deste, mesmo sob a proibição do rei, sabe que precisa enterrar o irmão morto, desobedece à lei da cidade e faz o que deve ser feito, obedecendo a leis não escritas, mas inscritas, ainda que saiba que pagará por isso. Também Harry Potter se insere nessa cadeia de heróis quando chega a momentos cruciais.

Harry ouviu Rony soltar uma exclamação e levantou a cabeça. Decidira o que fazer. - Vou descer - anunciou.

Ele não podia deixar de descer, agora que tinham encontrado a entrada para a Câmara, não se houvesse a mais leve, mínima, imaginária chance de Gina estar viva. (Rowling, 2000a, p. 254) 
Voltando à história... descobrimos que foi uma amiga de Harry, Gina, quem libertou o monstro, mas agiu sob o efeito de um encantamento. Franz (1987) afirma que um tema comum nos contos de fadas é a princesa que mata seus pretendentes, até ser redimida pelo herói e confessar que foi forçada pela maldição. Para essa autora, as pessoas dominadas por uma neurose se comportam de forma semelhante a uma pessoa enfeitiçada, pois são inconscientemente destrutivas para si mesmas e para os outros, ao agir de forma impulsiva. Na Antiguidade, acreditava-se que forças espirituais estavam em ação nos transtornos mentais, e, na Idade Média, os doentes mentais eram considerados feiticeiros e eram queimados nas fogueiras. Esse enfeitiçamento é o que acontece atualmente, por exemplo, com as compulsões, cada vez mais comuns e mais variadas, como as compulsões alimentares, sexuais ou de consumo, para citar algumas. A compulsão de consumo talvez seja a que melhor caracteriza a nossa época pósmoderna: o indivíduo vê o objeto e sente que não é ninguém sem ele, que precisa dele desesperadamente. É como se, novamente, o Ser fosse definido pelo Ter. Quando o feitiço acaba, ao acordar, o sujeito se sente mais vazio do que nunca, pois percebe que o objeto, na maioria das vezes, Ihe é inútil, ou ainda que não tapa o vazio que acreditava poder preencher com ele.

Ao final de cada livro, Harry volta para a casa dos tios. É como voltar à realidade depois de um sonho. E, novamente, em Harry Potter e o Prisioneiro de Azkaban (Rowling, 2000c), o herói se encontra em um momento de desespero quando a magia retorna à sua vida. Depois de mais umas férias torturantes com os tios, Harry lança um feitiço em um momento de raiva e foge de casa, temendo ser expulso da escola - pois não tem permissão para usar magia nas férias - sem saber o que fazer ou para onde ir. Nesse momento, aparece o Nôitibus, um ônibus de transporte para bruxos perdidos, que o leva de volta ao seu mundo mágico. Mas nem tudo são flores também no mundo dos bruxos, pois qualquer criador de histórias, fantasias ou sonhos sabe que, para haver uma reação, é preciso uma ação, para haver um efeito, é necessária uma causa. Portanto, para que as aventuras aconteçam, é preciso que uma crise ameace a ordem; para que Harry seja herói, é preciso haver dificuldades a enfrentar. Nesse livro, a autora nos apresenta a figura sombria dos Dementadores, seres que guardam a prisão dos bruxos, Azkaban, e que se alimentam tirando as lembranças felizes das pessoas, o que deixa nelas um sentimento de profunda infelicidade. Corso e Corso (2006) compara os dementadores com os efeitos de um dos grandes males da atualidade, que são os fenômenos depressivos:

Os Dementadores roubam a força vital,
sugam as boas lembranças. Depois de
encontrar um deles, uma pessoa se sente
como se nunca mais fosse ser feliz na
vida. Ser influenciado por eles assemelha-
se a viver num pesadelo do qual não se
consegue acordar. Mas é preciso esclarecer
que eles não oferecem um conteúdo que
nos faça sofrer, apenas criam o clima para
que fiquemos reduzidos a nossa pior face.
(p. 265)

As pessoas sob efeito da depressão estão abaladas em sua capacidade de sentir prazer na vida, ou com a vida. Também é mais difícil se apegar às partes saudáveis da personalidade (as memórias boas que os Dementadores sugam) e fica mais fácil, em contrapartida, apegar-se à culpa, à desesperança, à solidão. A descrição que as personagens fazem do sentimento despertado pela proximidade com os Dementadores - 
"é como se nunca mais fosse me sentir feliz novamente" - quase fala por si mesma. Ainda há na história o chamado "beijo" do Dementador, que é reservado para criminosos muito perigosos. Esse beijo não mata, mas esvazia o corpo da sua alma, e a pessoa passa a viver uma pseudo-existência, o que remete mais uma vez à sensação de esvaziamento e apatia que é sentida pelas pessoas em estados depressivos.

Em Harry Potter e a Ordem da Fênix (Rowling, 2003), Harry e os amigos já aparecem como adolescentes ao lidar com os eternos problemas da identidade infantil ou adulta, mostrado pelo fato de serem considerados crianças demais para participar da Ordem que se propõe a lutar contra Voldemort e seus seguidores, apesar de já terem vivido aventuras maiores que muitos dos seus membros. Como não são aceitos no grupo dos adultos, os adolescentes se rebelam e formam secretamente o seu próprio grupo de resistência, em que estudam matérias que não estão sendo ensinadas na escola, e preparam-se para a luta contra Voldemort. Qualquer semelhança com os movimentos estudantis de revolta, preparados em reuniões secretas, de onde muitas vezes era preciso fugir correndo, como fazem as nossas personagens, não pode ser mera coincidência. É como se Harry Potter questionasse nesse momento a aceitação passiva do mundo contemporâneo, assistindo às corrupções, misérias e violências como um espectador televisivo, amalgamado à tão comentada cultura do espetáculo, em que os fatos se tornaram notícias. Aliás, a chegada à escola de uma cruel Inquisidora, que proíbe qualquer organização ou manifestação fora dos padrões estabelecidos por ela, reflete os tempos da "repressão", tanto a repressão histórica, social, que se manifestou de formas sutilmente diferentes em vários lugares do mundo, quanto a repressão que a sociedade impõe aos impulsos dos indivíduos, conforme teoriza Freud (1930/1976) em "O Mal-Estar na Civilização". A adolescência é justamente o momento de testar os limites dessas imposições. É o momento em que as regras dos pais, bem como as regras sociais, parecem absurdas, sem sentido e, sobretudo, injustas. Na falta de diferenciação entre as gerações, como comentamos acima, os acirramentos se dão muitas vezes entre os indivíduos da mesma geração, através da formação de "tribos" e da intolerância. Quando jovens saem às ruas perseguindo homossexuais, mendigos, prostitutas - qualquer um que seja diferente deles - comportam-se de forma semelhante aos seguidores de Voldemort em relação aos que não têm filiação bruxa, que nasceram em famílias de trouxas.

Indícios das responsabilidades da adolescência também se vêem presentes em uma audiência a que Potter precisa comparecer por ter executado um feitiço fora da escola, mostrando que já não se pode fazer certas brincadeiras impunemente, é preciso agora se responsabilizar pelos seus atos. Justamente, um dos principais objetivos terapêuticos é dar condições aos nossos pacientes de se responsabilizaram por sua própria história e por seus próprios desejos, com um movimento que passa de olha só o que fizeram comigo para isto é o que eu posso fazer com o que / apesar do que fizeram comigo. Esse movimento precisa ser feito tanto em nível individual quanto em nível cultural, pois não basta a queixa social das condições de subjetivação do indivíduo pós-moderno, é preciso ir além disso. É aqui que nossa responsabilidade profissional abre as portas do consultório clínico e "cai" no mundo. É necessário reconhecer, no entanto, a dificuldade de tal responsabilização em uma sociedade que 
valoriza a época da juventude, da infância, das poucas preocupações. Na história de Harry, há uma personagem, Luna, que vive "no mundo da lua", diz coisas sem sentido e parece flutuar pelo mundo, sem tensões. Ela representa esse nosso desejo e também o desejo de Harry, de permanecermos alheios, infantilizados, sem nos envolvermos com a realidade que nos cerca, cerceia, oprime.

Mas talvez o tom maior, a partir de Harry Potter e a Ordem da Fênix até o último livro da série, é de que chega uma hora na vida de toda criança, que vira adolescente, que precisa tornar-se adulto, em que é preciso deixar para trás o conforto e a proteção dos pais. Harry nunca teve essa experiência, mas agora enfrenta a decepção com o pai, pois conhece histórias de seu passado das quais não consegue se orgulhar, bem como a morte das duas personagens que representavam para ele um papel paterno, o padrinho e o diretor Alvo Dumbledore, o que o faz retomar a questão da perda dos pais como heróis da infância. Agora Harry percebe que terá de lutar contra Voldemort sozinho, confiando em suas próprias forças, vencendo por si mesmo o mal que, na verdade, está dentro dele. A saga desse herói contemporâneo parece querer mostrar a repetição do desamparo da orfandade, para além das escolhas de Harry, simbolizando a necessidade de o homem atual - ou o desejo? - fazer-se por si mesmo, e a compreensão de que, no mundo, estamos por nossa própria conta. Novamente, a saga de Harry Potter possibilita identificações com o sujeito contemporâneo a partir do esfumaçamento da transmissão cultural. Já que não há uma tradição, uma genealogia, uma aculturação que funde o sujeito, criase a ilusão de que o sujeito se funda a si mesmo.
Em Harry Potter e o Enigma do Príncipe (Rowling, 2005), Harry apreende que não poderá simplesmente matar Voldemort, mas terá que lidar com sua alma dividida em sete partes, percebe que o inimigo somente seria vencido quando ele encontrasse e destruísse essas partes. Algumas dessas relíquias ele só destruirá no final, em Harry Potter e as Relíquias da Morte (Rowling, 2007), quando fará Voldemort desaparecer do mundo bruxo. Essas questões nos remetem ao que Lacan (1997) chama de segunda morte, para além da morte do corpo, a morte simbólica, a anulação, o remetimento à inexistência algo que já se tentara fazer no mundo bruxo ao não pronunciar o nome de Voldemort, chamando-o de aquele-que-não-deve-sernomeado, ou de você-sabe-quem. Calligaris (1993) relaciona esse tema da segunda morte com os atentados terroristas, mostrando que o que se busca nesses atentados é destruir um patrimônio simbólico, mais do que a morte de seres humanos; o que se busca é a morte das simbologias. Mas, como o próprio autor reflete, "matar os símbolos é muito difícil" (p. 185). O autor ainda segue a reflexão abordando o que já comentamos acerca do cerceamento de semelhanças e diferenças - identificações - dentro de uma mesma geração, e levando às intolerâncias existentes.

Como a autora escreve em tempo real, um livro por ano, e também é apresentado um filme por ano, as crianças crescem e se desenvolvem ao mesmo tempo em que seu herói. Nos primeiros livros, a estrutura é mais simples, as aventuras demonstram a necessidade de deixar para trás certos aspectos infantis e ir assumindo lentamente novos papéis, através das lutas iniciáticas vividas por Harry. Conforme avança no tempo, os últimos livros se tornam cada 
vez mais sombrios, Harry se vê mais e mais solitário e sente que a responsabilidade de destruir Voldemort é só sua, já que não pode dividir seu peso com ninguém. É chegada, para o adolescente, a hora de abrir caminho sozinho no mundo e viver a vida, já que nenhum pai e mãe poderão viver por ele, embora os pais o quisessem, mas isso já é outra história. A respeito disso, retomando uma questão que deixamos em aberto, podemos nos questionar porque muitos heróis modernos e contemporâneos são órfãos ou desamparados. Antes de Harry Potter, já tivemos outros, não tão conhecidos, mas igualmente envolventes. Outras crianças confrontadas com situações aterradoras foram Susana, Lúcia, Pedro e Edmundo, de As Crônicas de Nárnia (Lewis, 2002), que tiveram de se mudar de Londres para o interior na época da guerra, deixando a companhia de sua mãe. Ora, por que será que essas crianças entraram em um simples guarda-roupa e foram sair em uma terra de faunos e feiticeiras? A pequena Mary Lennox, após perder os pais, também vai morar com um tio em sua sombria mansão, mas encontra um refúgio ao descobrir uma porta no muro que leva para O Jardim Secreto (Burnet, 2004). O herói de A História sem Fim (Ende, 2001), Bastian, fugindo de sua realidade de órfão, gordinho e covarde, entra em um livro e chega à Fantasia, uma terra onde ele é o salvador de todos, agora grande, forte e corajoso. Para não deixar de fora as histórias nacionais, temos A Terra dos Meninos Pelados, de Ramos (2004), em que um menino careca, que nos traz enquanto memória as crianças com câncer submetidas à quimioterapia, vai caminhando, amolado pelas gozações dos outros garotos da rua, e vai se afastando até entrar em Tatipirum, um lugar onde as plantas não têm espinhos e todos os meninos são carecas. É como se vivêssemos em uma sociedade órfã, sem herança, pois os canais que passavam aos mais jovens os ideais, os valores aos quais se apegar, bem como contra os quais se rebelar, estão obstruídos. Na falta de símbolos e verdades transmitidas e reelaboradas de pais para filhos, ou via instituições, as pessoas apegam-se ao mundo das imagens, dos objetos, para se sentirem menos incompletos; um mundo trouxa, desencantado e cruel.

Segundo Franz (1990), como já dissemos, as histórias compensam algo que está faltando em nível inconsciente, tanto no aspecto individual - uma história ou filme que a criança escolhe para repetir incessantemente - ou para compensar algo que falta a uma época ou situação histórica - narrativas que se repetem em sua estrutura básica, modificando enredos e personagens. A saga de Harry Potter é cheia de referências a noções de princípios, de certo ou errado, de tolerância às diferenças individuais e "raciais" (bruxos ou trouxas; sangue-puro ou sangueruim), de uma educação composta por regras formuladas com fundamento na tradição, no respeito ao outro e no bom senso. Mesmo quando burlam as regras - quase sempre - as personagens o fazem a partir de uma ética. Essas referências podem atrair inconscientemente as crianças e os jovens que sentem falta desses valores na realidade, em uma cultura marcada pelo narcisismo e pelo individualismo, por pessoas sem limites, com uma ecologia e solidariedade puramente estéticas, e Harry Potter aparece como um contraponto e uma compensação; como dissemos no início, como um pouco de magia trazido para a ordem do dia, em um dia escuro e espinhoso.

É preciso dar valor à magia, à imaginação, auxiliar as crianças, como bem disse Ribeiro (2004), a construírem impérios imaginários interiores para não precisarem pisar em seus 
semelhantes em busca de poder quando adultos. É preciso deixar que a menina se sinta bela como as princesas e construa aos poucos a sua beleza interior, para não vermos mais tantas mulheres "morrendo de fome" ou submetendo-se a cirurgias desnecessárias. É preciso auxiliar a criança a preencher-se, a formar idéias, para que não chegue à idade adulta odiando o que não conhece ou comprando o que não precisa. Enfim, podemos refletir
- e talvez agir - sobre o mal-estar na contemporaneidade se atentarmos mais para o que estamos mostrando, dizendo ou lendo para nossas crianças, pois toda revolução social parte do indivíduo, e é cuidando das crianças que estaremos preparando o futuro psicológico do mundo. Mas essa é outra história, talvez sem fim, e terá de ser contada em uma outra ocasião. 


\section{Referências}

\section{Daniela Botti da Rosa}

Mestranda em Letras e Lingüística - Análise do discurso

Psicóloga clínica

Especialista em Psicologia clínica

\section{Endereço para envio de correspondência:}

Rua: Durval Guimarães, 2036 ap. 502 - Ed: Guaraí

Ponta Verde - Maceió/AL

CEP: 57035060

E-mail: danibotti@ig.com.br

Recebido 04/05/2007 Reformulado 14/04/2008 Aprovado 07/06/2008

Bettelheim, B. (1980). A psicanálise dos contos de fadas (15a ed.). Rio de Janeiro: Paz e Terra.

Burnet, F. H. (2004). O jardim secreto. São Paulo: Scipione.

Calligaris, C. (1993). Sociedade e indivíduo. In M. Fleig (Org.), Psicanálise e sintoma social (pp. 183-196). São Leopoldo, RS: Unisinos.

Calligaris, C. (2000). A adolescência. São Paulo: Publifolha.

Campbell, J. (1990). O poder do mito. São Paulo: Palas Athena.

Corso, D. (1993). A parentalidade envergonhada. In M. Fleig (Org.), Psicanálise e sintoma social pp. 169-182). São Leopoldo, RS: Unisinos.

Corso, D., \& Corso, M. (2006). Fadas no divã: psicanálise nas histórias infantis. Porto Alegre: Artmed.

Ende, M. (2001). A história sem fim. São Paulo: Martins Fontes.

Ford, C. W. (1999). O herói com rosto africano: mitos da África. São Paulo: Summus.

Franz, M. L. von. (1987). O significado psicológico dos motivos de redenção nos contos de fadas (4a ed.). São Paulo: Cultrix.

Franz, M. L. von. (1990). A interpretação dos contos de fadas (5a ed.). São Paulo: Paulus.

Freud, S. (1976). O mal-estar na civilização. In Obras completas (Vol. 21). Rio de Janeiro: Imago. (Trabalho original publicado em 1930)

Freud, S. (1976). Romances familiares. In Obras completas (Vol. 9). Rio de Janeiro: Imago. (Trabalho original publicado em 1909)

Freyre, K. (Org.). (2001). A fantástica história dos contadores de histórias no reino do tudo é possível - histórias para acordar os homens. Recife: Edupe.

Lacan, J. (1997). O seminário - livro 7: a ética da psicanálise. Rio de Janeiro: Jorge Zahar.
Lacan, J. (2002). Os complexos familiares. Rio de Janeiro: Jorge Zahar.

Lemos, M. L. (2005). Cultura e desamparo: com a palavra os góticos. Correio da APPOA, Porto Alegre, (139), 17-23.

Lewis, C. S. (2002). As crônicas de Nárnia. São Paulo: Martins Fontes.

Ramos, G. (2004). A terra dos meninos pelados. Rio de Janeiro: Record.

Ribeiro, J. (2004). Contos de fadas: de coração desarmado para coração desarmado. São Paulo: Editora Ave Maria.

Rowling, J. K. (2000a). Harry Potter e a câmara secreta. Rio de Janeiro: Rocco.

Rowling, J. K. (2000b). Harry Potter e a pedra filosofal. Rio de Janeiro: Rocco.

Rowling, J. K. (2000c). Harry Potter e o prisioneiro de Azkaban. Rio de Janeiro: Rocco.

Rowling, J. K. (2001). Harry Potter e o cálice de fogo. Rio de Janeiro: Rocco.

Rowling, J. K. (2003). Harry Potter e a ordem da fênix. Rio de Janeiro: Rocco.

Rowling, J. K. (2005). Harry Potter e o enigma do príncipe. Rio de Janeiro: Rocco.

Rowling, J. K. (2007). Harry Potter e as relíquias da morte. Rio de Janeiro: Rocco.

Smadja, I. (2004). Harry Potter - as razões do sucesso. Rio de Janeiro: Contraponto.

Sófocles. (1997). Antígona. São Paulo: Paz e Terra.

Stahlschmidt, A. P. M. (2006). Horror e humor na literatura infantil. Correio da APPOA, Porto Alegre, (152), 44-50.

Viorst, J. (2005). Perdas necessárias (31a ed.). São Paulo: Melhoramentos. 